\title{
PAIXÃO, DEMOCRACIA E DELIBERAÇÃO EM HOBBES E WALZER
}

\author{
Cláudio R. C. LEIVAS ${ }^{1}$
}

- RESUMO: O artigo examina a relação entre paixão, democracia e deliberação no pensamento de Hobbes e no de Walzer. São apresentadas as razões pelas quais esses dois pensadores posicionam-se de forma crítica no concernente às deliberações no âmbito de governos democráticos. A relação entre razão e paixão é também examinada no interior do problema central de nosso estudo comparativo.

- PALAVRAS-CHAVE: democracia, deliberação, razão, paixão.

Hobbes acredita que todo processo deliberativo envolve uma sucessão alternada de desejos, aversões, esperanças e medos relativos à ação a ser seguida ou a seu impedimento. A deliberação humana é antes de tudo passional. Inicia quando nos sentimos motivados para fazer algo que consideramos bom para nós, mas pode ser interrompida a qualquer momento, se detectamos indícios de que a ação em questão pode trazer-nos algum dano ou prejuízo. A passagem da deliberação para a realização da ação deliberada é intermediada pela faculdade da vontade. A vontade ou o querer humano põe fim à liberdade de escolhermos outro desdobramento concernente à ação proposta. Quer isto dizer que, se o desejo (ou seja, a escolha de praticar a ação) é o último elemento determinante num processo deliberativo, o desejo é determinado como vontade. Por outro lado, se é a aversão (ou seja, a escolha de não praticar a ação) o último elemento determinante, é a aversão que se chamará vontade. O Capítulo VI do Leviatã explica o termo "deliberação" da seguinte forma:

1 Professor adjunto do Departamento de Filosofia da Universidade Federal de Pelotas (UFPEL). Artigo recebido em 10/2009 e aprovado em 12/2009. 
Quando surgem alternadamente no espírito humano apetites e aversões, esperanças e medos, relativamente a uma mesma coisa; quando passam sucessivamente pelo pensamento as diversas consequências boas ou más de uma ação, ou de evitar uma ação; de modo tal que às vezes se sente um apetite em relação a ela, e às vezes uma aversão, às vezes a esperança de ser capaz de praticá-la, e às vezes o desespero ou medo de empreendê-la; todo o conjunto de desejos, aversões, esperanças e medos, que se vão desenrolando até que a ação seja praticada, ou considerada impossível, leva o nome de deliberação. (Hobbes, 2003, p. 54-5)

A pergunta óbvia a ser feita no presente momento é certamente sobre a função ocupada pela razão num processo deliberativo de tipo hobbesiano. A clara referência à extensão da deliberação a animais não humanos é um indicativo de que a racionalidade é acidental, e não substancial, à deliberação em si mesma. Acrescente-se a isso que em Hobbes a razão é adquirida durante nossas experiências de vida. Ela não é uma faculdade natural. Nascemos dotados com movimentos voluntários chamados paixões (além daqueles movimentos que nos inserem na classe dos animais) e deliberamos sobre o que nos agrada (desejo) ou desagrada (aversão) desde o nascimento, movidos que somos (consciente ou inconscientemente) pelo desejo básico de preservação de nossas vidas. Mas em determinado momento nos tornamos racionais. O homem é um composto de movimento animal, movimento passional e razão calculadora (em Hobbes, raciocinar é calcular). O ser humano, diferentemente dos outros animais, é capaz de incluir o cálculo para escolher a melhor ação a ser tomada ao deliberar sobre a melhor forma de realizar seus desejos e interesses ou evitar possíveis prejuízos a si próprio e aos outros. A razão tem, pois, em Hobbes uma função acessória: por meio do cálculo das consequências, ajudar as tomadas de decisão relativas à realização do desejo humano. Em outra parte do Leviatã Hobbes diz que "os pensamentos são para os desejos como batedores ou espias, que vão ao exterior procurar o caminho para as coisas desejadas" (Hobbes, 2003, p. 66).

A razão trabalha em conjunto com a paixão, ajudando esta na consecução de seus objetivos. O que não exclui a possibilidade de haver atos voluntários contra a razão: "A definição da vontade vulgarmente dada pelas Escolas, como apetite racional, não é aceitável. Porque, se assim fosse, não poderia haver atos voluntários contra a razão" (Hobbes, 2003, p. 55). Vontade racional é, pois, um termo equívoco em Hobbes, da mesma forma que o termo deliberação (puramente) racional. A relação razão-paixão é, porém, uma relação de ajuda mútua antes de ser uma relação de dicotomia (razão $\times$ paixão) e jamais uma relação em termos senhoriais em que a paixão submete-se à razão de forma submissa (= paixão como serva da razão). Na esfera da teoria política o tratamento dispensado por Hobbes à relação razão- 
paixão ${ }^{2}$ toma a seguinte direção: a passagem do estado natural para o estado político requer a associação entre razão e paixão para fazer frente aos indecisos ou interesseiros (esses últimos no sentido negativo de obter-se vantagens individuais a curto prazo quando surge a possibilidade de uma paz duradoura a longo prazo) no momento do pacto fundador da nova entidade política (Estado moderno). Hobbes diz o seguinte no final do Capítulo XV do Leviatã:

As paixões que fazem os homens tender para a paz são o medo da morte, o desejo daquelas coisas que são necessárias para uma vida confortável, e a esperança de consegui-las através do trabalho. E a razão sugere adequadas normas de paz, em torno das quais os homens podem chegar a acordo. Essas normas são aquelas a que por outro lado se chama leis de natureza, das quais falarei mais particularmente nos dois capítulos seguintes. (Hobbes, 2003, p. 111)

Em resumo, as leis naturais são leis da razão direcionadas para forçar (isto é, convencer com base em argumentos sólidos) o cumprimento de acordos no sentido de sair de um estado de guerra (estado natural) e adentrar num estado de paz (estado político). Como as leis e as promessas são frágeis, fáceis de quebrar quando alicerçadas apenas nas palavras, é preciso o auxílio da paixão-medo (no caso, o medo de ser punido pela espada da Justiça) para motivar efetivamente os homens a cumprir os pactos feitos. A paixão política do medo está na base, portanto, da fundação do estado político moderno. É declaradamente uma paixão positiva posicionada de forma estratégica para contrapor-se a uma série de paixões negativas (cobiça, inveja, raiva, etc.) que obstaculizam o êxito dos acordos necessários ao surgimento da civilização. Uma vez criado o deus mortal da política (o deus Leviatã é assim chamado por ter um poder irresistível e por não ter medo de nada, em analogia ao Deus imortal dos crentes), a paixão política do medo persiste como um dos mecanismos mais eficientes para forçar o cumprimento das leis civis e evitar a desobediência civil e todo tipo de desordem na esfera pública.

As deliberações nessa esfera resultam em leis racionais que devem ser seguidas por todos, com algumas raras exceções, por exemplo, quando o

2 A história política ocidental é um testemunho incrivelmente rico das paixões (na maior parte, violentas e belicosas) como causas motivadoras da alteração dos acontecimentos e do curso de vida das coletividades humanas. Por vezes travestidas por valores religiosos (pensemos na vingança e no ódio envolvidos na intolerância religiosa que motivou os massacres "em nome da fé cristã" na época das Cruzadas), por vezes ainda sob a aparência de uma racionalidade pública que busca legitimar o ataque em nome da segurança da nação (exemplo disso é a recente invasão do Iraque, em que paixões de um governante alucinado por fazer a guerra forjou provas e manipulou parte da opinião pública para obter o apoio necessário ao ato belicoso). 
Estado não consegue salvaguardar a vida de seus cidadãos, caso este em que, como Hobbes admite, roubar para alimentar-se é uma necessidade básica (ou melhor, um dos direitos inalienáveis da humanidade, a saber, o direito natural à salvaguarda da vida e dos membros), superior às leis inventadas pelo homem para a proteção da propriedade pública ou privada. Mas as deliberações públicas envolvem elementos racionais e passionais que antecedem à tomada de decisão dos governantes soberanos quanto aos assuntos relacionados à res publica. A razão pública do Estado é frequentemente alterada pelas paixões do soberano-representante.

\section{I - Democracia e deliberação: Hobbes}

A concepção de Hobbes de democracia deliberativa é justaposta em Do cidadão nos seguintes termos:

Onde a monarquia mais se distingue da aristocracia e da democracia é no fato de que nestas duas últimas têm de estar marcados lugares e datas para a deliberação e consulta dos negócios, isto é, para assegurar seu exercício efetivo em todos os lugares e datas. Pois tanto o povo quanto os nobres, não constituindo pessoas naturais, necessariamente precisam reunir-se. (Hobbes, 1992, p. 147)

Diferentemente do que ocorre em um governo monárquico ${ }^{3}$ (isto é, no governo de um só), em um governo democrático (isto é, no governo de muitos) as deliberações públicas são realizadas por ocasião de reuniões ou assembleias a que comparece grande números de pessoas. Em uma monarquia, pensa Hobbes, o fato de um indivíduo natural ser o portador da pessoa pública do Estado acaba por suspender a rígida distinção entre deliberação individual e deliberação pública. Hobbes pode então concluir a passagem acima dizendo que "o monarca, que por natureza é uno, sempre está atualmente capacitado a executar sua autoridade" (Hobbes, 1992, p. 147). O governo popular ("popular commonwealth"), porém, por ser constituído por muitos, requer duas coisas para se manter: "a convocação perpétua de assembleias" (nas quais é formado o demos, ou povo) e "a maioria de votos" (a qual é responsável pela formação do tò krátos, ou o poder) (Hobbes, 1992, p. 147).

As três formas de governo (conforme estabelecidas pelo Do cidadão e pelo De Corpore Politico) sofrerão uma modificação estrutural com o surgimento do Leviatã. Nessa obra Hobbes introduz um conceito fundamental para a teorização e formação do estado político moderno: o conceito de re-

3 Hobbes refere-se à monarquia clássica ou tradicional. 
presentação política. Ausente em seus escritos políticos anteriores, a representação política permite agora uma nova diferenciação quanto às formas de governo:

A diferença entre as repúblicas consiste na diferença do soberano, ou pessoa representante de todos e cada um dos membros da multidão... pois o representante é necessariamente um homem ou mais de um, e caso seja mais de um a assembleia será de todos ou apenas de uma parte. Quando o representante é um só homem, a república é uma monarquia. Quando é uma assembleia de todos os que se uniram, é uma democracia, ou governo popular. Quando é uma assembleia apenas de uma parte, chama-se-lhe aristocracia. (Hobbes, 2003, p. 158-9)

Uma democracia é, portanto, uma espécie de governo em que o soberano-representante é o próprio povo reunido em assembleia (uma assembleia de todos). As deliberações públicas do povo são inseridas no que mais tarde ficou conhecido como democracia representativa. Enfim, a teoria da democracia de Hobbes contém elementos deliberativos e representativos que nos permitem chamá-la de democracia representativa deliberativa. Diferentemente da democracia deliberativa atual, a teoria da democracia de Hobbes envolve o processo do sufrágio universal nas deliberações públicas. É possível assinalar como uma segunda diferença a que atribui às deliberações públicas paixões (nos moldes da deliberação individual da forma concebida por Hobbes)? Prima facie, as paixões associadas à democracia sempre foram consideradas como sinônimo de anarquia, desordem e degradação social. Qual a relação, portanto, entre democracia, deliberação pública, razão e paixão em Hobbes? É nosso propósito responder a essa indagação antes de examinar o modo pelo qual Walzer trabalha algumas dessas questões em seu recente livro Política e paixão.

O começo da reflexão hobbesiana aponta para a relação entre poder político ${ }^{4}$ e aquilo que em Tocqueville recebe o nome de tipologia das formas de governo. Na visão de Hobbes, "o poder é sempre o mesmo em todas as formas [de governo], se estas forem suficientemente perfeitas para proteger os súditos" (Hobbes, 2003, p. 157). A natureza do poder soberano é inalterável quanto ao fato de ele pertencer a um (monarquia) ou mais homens (aristocracia), ou a todos (democracia). O que é conta (na diferenciação qualitativa das formas de governo) não é o somatório de poder que uma forma de

4 No Capítulo X do Leviatã Hobbes diz que "a natureza do poder é idêntica à da fama, dado que cresce à medida que progride". Ele define então a seguir o poder político como aquela espécie de poder resultante de uma composição de poderes "da maioria dos homens, unidos por consentimento numa só pessoa, natural ou civil, que tem o uso de todos os poderes deles na dependência de sua vontade" (Hobbes, 2003, p. 76). 
governo teria (ou tenderia a ter) sobre uma outra e que, segundo essa hipótese, a constituiria como referência na forma de governar uma nação. O que realmente interessa na avaliação qualitativa das formas de governo é a "diferença de conveniência", isto é, a "capacidade para garantir a paz e a segurança do povo" (Hobbes, 2003, p. 160). Sendo o salus populis (isto é, a segurança do povo) a causa final ou objetivo último da fundação do estado político, é na habilidade voltada para a manutenção da ordem pública que reside a diferenciação das formas de governo. Veremos a seguir que a relação entre razão e paixão está na base desse problema.

As paixões são avaliadas como boas ou más, inicialmente, no que diz respeito à passagem do estado natural para o estado político (isto é, no que diz respeito à fundação do Estado). A paixão do medo é boa porque necessária para forçar a racionalidade inerente aos acordos concernentes ao cumprimento dos pactos feitos. Essa paixão é boa especialmente porque fala a linguagem das paixões e pode contrapor-se assim passionalmente (quando os argumentos racionais contidos nas leis naturais são obstaculizados) às paixões más, isto é, aquelas que são contrárias à fundação da ordem pública, "as quais nos fazem tender para a parcialidade, o orgulho, a vingança e coisas semelhantes" (Hobbes, 2003, p. 143).

A preferência de Hobbes por um governo monárquico em detrimento de um governo popular é sustentada por uma série de ponderações que principia com um argumento (difícil de ser defendido) ${ }^{5}$ baseado na relação entre razão e paixão. Hobbes assume que "em geral as paixões humanas são mais fortes do que a razão" (observe-se que ele não diz que as paixões são sempre mais fortes que a razão). Ele estava convencido (ou queria convencer, retoricamente) de que as paixões individuais dos governantes teriam menos efeitos prejudiciais à administração pública no caso de uma possível identificação entre interesse pessoal e interesse público, o que seria viável apenas no governo de um só, isto é, numa monarquia. Estabelecida essa identidade, o deliberar e o agir do monarca contempla paixões e razões pessoais que de alguma forma conduzem ao bem comum, já que na monarquia "o interesse pessoal é o mesmo que o interesse público" (Hobbes, 2003, p. 160). Numa democracia, porém, "a prosperidade pública concorre menos para a fortuna pessoal [...] do que, muitas vezes, uma decisão pérfida, uma ação traiçoeira ou uma guerra civil" (Hobbes, 2003, p. 161). A segunda ponderação a favor da monarquia traz a clássica associação da paixão com o fogo que queima e da razão com a luz que ilumina. A questão

5 Poderíamos acrescentar a essa dificuldade os recentes casos de desvio de dinheiro público na Inglaterra. Mas o caso se deu no Parlamento. Além disso, a monarquia inglesa atual é de tipo diferente daquela em que pensava Hobbes. 
versa sobre os conselheiros do governante. Um monarca, diz Hobbes, "tem a possibilidade de ouvir as pessoas versadas na matéria sobre a qual está deliberando [...] com a antecedência que quiser em relação ao momento da ação, e com o sigilo que quiser", o que não ocorre numa assembleia democrática deliberativa, em que os longos discursos públicos podem incitar a multidão a ações contrárias à ordem pública, e isso porque, segundo Hobbes, "o entendimento, submetido à chama das paixões, jamais é iluminado, mas sempre ofuscado" (Hobbes, 2003, p. 161). Hobbes dedica um capítulo inteiro do Leviatã a examinar a natureza do conselho e a função dos conselheiros no interior de um estado político. O que nos interessa aqui é assinalar a parte do Capítulo XXV do Leviatã ("Do conselho") em que Hobbes volta ao ponto das deliberações sigilosas para mostrar o perigo da quebra de segredo num governo popular: "Nas deliberações que devem ser mantidas em segredo (o que é extremamente frequente nas questões públicas), os conselhos de um grande número, e sobretudo os das assembleias, são perigosos" (Hobbes, 2003, p. 224).

\section{II - Democracia e deliberação: Walzer}

O posicionamento de Walzer sobre a democracia deliberativa envolve alguns elogios e muitas objeções. No compreender de Walzer, a democracia deliberativa é a versão americana das teorias alemãs da ação comunicativa e do discurso ideal. Reconhece-a como uma verdadeira teoria ${ }^{6}$ e que muitos de seus argumentos são convincentes, mas acrescenta a seguir que ela não possui as mesmas pretensões de rigor filosófico das teorias alemãs do discurso, em parte devido ao fato de que seus teóricos "não se concentram nas pressuposições racionalmente verificáveis do discurso humano, e sim na organização prática e nos resultados prováveis das discussões políticas controladas por normas" (Walzer, 2008, p. 131). Não obstante isso, acredita que a democracia deliberativa é uma "evolução interessante do liberalismo americano", que consiste na passagem de um discurso de direitos para um discurso de decisão em que o modelo preferencial para as deliberações e tomadas de decisão é o tribunal de um júri. Os teóricos da democracia deliberativa, em resumo, têm o seguinte propósito em vista:

Chegar a decisões através de um processo racional de discussão entre iguais, que ouvem respeitosamente os pontos de vista do outro, examinam com cuidado os dados disponíveis, ponderam as possibilidades alternativas, discutem sobre a perti-

6 Pertencente à esfera pública. 
nência e o valor de cada uma delas e depois escolhem a melhor política para o país ou a melhor pessoa para o cargo. (Walzer, 2008, p. 132-3)

Walzer não pretende negar que deliberamos "nesse sentido mais amplo" em certas circunstâncias. Também não pretende negar a importância da deliberação para teorias políticas democráticas contemporâneas. Seu principal objetivo é "compreender como a deliberação se encaixa num processo político democrático profundamente não-deliberativo". Diferentemente de Hobbes, Walzer aceita a identificação entre deliberação e razão, o que fica claro quando ele diz que "governar é uma atividade deliberativa, mas os prazeres do comando não são, de modo algum, completamente racionais, senão as pessoas não buscariam o comando com tanta paixão" (Walzer, 2008, p. 148). A deliberação pura ou em si é para ele uma deliberação puramente ou em si mesma racional. É nesse contexto que ele buscará compreender valores políticos que estão além da razão e que na maioria das vezes entram em conflito com ela numa variedade expressiva de atividades políticas. Alguns desses valores são "a paixão, o comprometimento, a solidariedade, a coragem e a competitividade". São catalogadas e discutidas 14 atividades $^{7}$ no total para mostrar de que forma pode-se pensar a política indo além da deliberação racional.

Observemos por ora que, embora Hobbes privilegie as paixões no processo deliberativo, ele considera que as deliberações democráticas são perigosas justamente pelo componente passional envolvido nas deliberações públicas, daí sua preferência pela deliberação de uma só pessoa, na figura do monarca. É de se perguntar, porém, se o modelo deliberativo de tribunal de júri não seria atrativo a Hobbes no sentido de que contornaria a questão - inadequada e perigosa - das deliberações que envolvem multidões. A lista de atividades políticas não-deliberativas apresentada por Walzer pertence a uma série que inclui a organização e a mobilização na prática política. O fato da inerência do conflito e das paixões na vida política (lembremos que a própria democracia é concebida por alguns como "a legitimação do conflito") conduz a uma estranheza teórica quanto a essa proposta de isolamento de elementos passionais em atos deliberativos com pretensões puramente racionais. A democracia deliberativa, enfim, busca chegar a decisões por um modelo de objetividade racional em que o ponto de partida é "o pressuposto-padrão de que existe um único resultado justo para o julgamento" (Walzer, 2008, p. 149). Em nota, Walzer cita a definição,

7 Lista de atividades não-deliberativas, segundo Walzer: educação política, organização, mobilização, manifestação, declaração, debate, negociação, a prática do lobby, sufrágio, corrupção, trabalho subalterno, governo (Walzer, 2008, p. 134-48). 
dada por Rawls, da Suprema Corte como o "modelo institucional" da razão pública, o que envolve uma separação radical entre deliberação e política (Walzer, 2008, p. 149). Dessa forma, podemos perceber que Walzer, para compreender a democracia deliberativa, estabelece uma linha divisória entre deliberação racional e paixão política. Mais tarde ele dirá que a dicotomia razão-paixão é algo que não existe. Poderá ele admitir uma deliberação envolvendo elementos racionais e passionais? A resposta é não. Deliberação é "discussão racional". Walzer pretende simplesmente que a deliberação democrática não seja isolada da vida política, que a "cultura da discussão" preconizada por ela entre em contato com as atividades políticas, pois, de acordo com Walzer:

Minha esperança de que a deliberação ocorra paralelamente junto com outras coisas terá mais probabilidade de se concretizar se a atividade política for conduzida abertamente, com total publicidade, por ativistas e funcionários públicos democraticamente responsáveis. Se democracia exige discussão, a cultura da discussão é acentuada e fortalecida pelas instituições e práticas democráticas convencionais as eleições, a competição entre os partidos, uma imprensa livre. (Walzer, 2008, p. 157)

A conclusão de Walzer é importante para nossos propósitos porque de certa forma ratifica a principal crítica de Hobbes à democracia deliberativa como forma de governo. Com efeito, de acordo com o que diz Walzer, o problema central da democracia deliberativa é o seguinte: "A deliberação em si não é uma atividade que se preste a demonstrações de massa". O que não significa, continua Walzer, que pessoas comuns não tenham a capacidade de usar a razão, e sim que é simplesmente implausível que multidões de pessoas (isto é, que 300 milhões, 1 milhão ou 100 mil) "possam raciocinar em conjunto" (Walzer, 2008, p. 158). Walzer admite que chegou a essa conclusão com base em um exemplo de deliberação democrática dada por James Fishkin, ${ }^{8}$ o qual pode ser disposto da seguinte forma: propõe-se

o estabelecimento de júris de cidadãos, aos quais se pediria que decidissem sobre questões cruciais das políticas públicas, ou que ao menos propusessem soluções para elas. Na formação dos júris, as amostragens científicas substituiriam as formas usuais da política eleitoral, e, nas reuniões dos júris, a discussão racional substituiria as formas usuais do debate político. (Walzer, 2008, p. 158)

Mas, ao contrário de Hobbes, Walzer é um liberal. Ele teme que o modelo de democracia deliberativa de tipo "tribunal de júri" afaste as pessoas de processos decisórios, enfraquecendo com isso a necessária oposição às

8 Cf. J. Fishkin, Democracy and Deliberation (1991). 
"hierarquias estabelecidas da riqueza e do poder" (Walzer, 2008, p. 158). "Os júris serão perigosos", segundo Walzer, "se a amostragem substituir as pessoas nela representadas" (Walzer, 2008, p. 158). Em outros termos, Hobbes também considerava perigosa a democracia deliberativa. O perigo para ele estava justamente no que a democracia deliberativa contemporânea busca evitar: as deliberações que envolvem multidões politicamente apaixonadas. Esse componente quantitativo inviabilizou a antiga democracia direta. A inclusão do conceito de representação política no Leviatã não foi suficiente para convencer Hobbes de que a ideia de democracia representativa poderia solucionar o perigo inerente às discussões públicas envolvendo multidões humanas. Porque deliberação sempre envolve paixão e razão, a solução, para ele, era que um só deliberasse sobre questões de política pública. A solução dos democratas deliberativos da atualidade para conter o perigo das deliberações em massa são as discussões racionais num tribunal de júri. Em contrapartida, esses tipos de deliberação são politicamente perigosos para o interesse público. Acreditamos que a democracia representativa por sufrágio universal ainda não tem concorrente à altura na atualidade.

$\mathrm{O}$ que pretendemos inquirir a seguir pode ser posto nos seguintes termos: o que Walzer tem a dizer sobre a relação razão-paixão? Walzer não deseja diminuir a força destrutiva das paixões na política. Cita Hobbes no início do capítulo que dá título ao livro Política e paixão para esclarecer, adequadamente, que as guerras geradas pelas paixões são de tipo diferente da guerra determinantemente racional de todos contra todos tal qual descrita por Hobbes:

A paixão ajuda a promover a guerra, não de todos contra todos... [pois a guerra descrita por Hobbes é uma atividade racional, gerada pela desconfiança universal], mas sim a guerra de alguns contra alguns, de grupo contra grupo, nas quais a força motriz é o puro ódio. (Walzer, 2008, p. 162)

Walzer cita um pouco depois Hume, para quem a razão era escrava das paixões, e que acreditava ser o zelo religioso uma paixão a que, esperava, homens e mulheres conseguissem resistir. Walzer evoca uma série de fatos históricos ${ }^{9}$ para ilustrar o surgimento pontual das piores das paixões políticas - isto é, a certeza dogmática, a ira, a inveja, o ressentimento, a intolerância e o ódio - e assim provocar a seguinte indagação: deveríamos eliminar a paixão política para permitir que as melhores qualidades da mente isto é, a sensatez, o ceticismo, a ironia e a tolerância - triunfem na arena

9 A repressão puritana, o terror da Revolução Francesa, os expurgos stalinistas e os massacres e deportações do nacionalismo contemporâneo. 
política? Substituir o calor pela luz? O fogo das paixões pelas luzes do entendimento? Impossível, afirma Walzer, muito embora desejável. O motivo principal é que a política é feita de conflitos, oposições, discordâncias e lutas. Uma separação radical entre razão e paixão pode impedir a esperança de grandes conquistas, visto que "a política tem a ver sobretudo com pessoas que possuem convicção e paixão, razão e entusiasmo, numa combinação sempre instável" (Walzer, 2008, p. 175).

Walzer acredita que estender "a legitimidade racional à paixão política" pode ser útil para revisar a teoria liberal, que ultimamente se tem preocupado em demasia com "a construção de procedimentos deliberativos desapaixonados" (Walzer, 2008, p. 183). Com isso poderíamos compreender e explicar melhor os vínculos e os conflitos sociais. É correto dizer que a razão é conceitualmente distinta da paixão. Na prática, porém, diz Walzer, elas estão sempre enredadas: "Assim, tenho a pretensão de tornar menos distinta a linha entre razão e paixão: racionalizar as paixões (algumas delas) e apaixonar a razão" (Walzer, 2008, p. 184). Essa parece ser a fórmula encontrada por Hobbes para justificar a passagem do estado natural para o estado político: racionalizar a paixão política do medo. ${ }^{10}$ De fato, diz Walzer, "existem combinações 'boas' e 'más' de razão e paixão, as quais distinguimos racionalmente e apaixonadamente" (Walzer, 2008, p. 185). "Não é o caso aqui de dizer que os líderes políticos não devam deliberar de modo racional e desapaixonado" (Walzer, 2008, p. 186), adverte Walzer, mesmo que em nome de uma Realpolitik puramente racional muitos crimes tenham sido cometidos, em particular por líderes que reprimiram seus sentimentos de solidariedade. O fato é que, antes de esses líderes tomarem decisões puramente racionais, eles precisam chegar ao poder e, segundo Walzer, "a competição pelo poder é o principal modelo de vida política" (Walzer, 2008, p. 187). Parece que encontramos aqui uma das teses da filosofia política hobbesiana. Mas devemos observar que o estabelecimento do poder político em Hobbes ocorre mediante acordos mútuos que visam justamente a pôr fim à competição de poder entre indivíduos humanos, uma vez que essa competição por poder e mais poder era uma das causas geradoras da guerra no estado natural. Em um estado de natureza internacional, de tipo hobbesiano, a competição pelo poder é infinita, já que não há em Hobbes a possibilidade de um poder supremo na esfera internacional para garantir a estabilidade política entre as nações. Tampouco existe em Hobbes uma moralidade das leis naturais regrando as relações internacionais, como encontramos em Grotius, e menos ainda uma confederação de nações com objetivos de efetivar a paz perpétua, como em Kant. Walzer conclui Política e paixão da seguinte forma:

10 Tese sustentada por Strauss em A filosofia política de Hobbes. 
As dicotomias que opõem a energia apaixonada a algum tipo de racionalidade baseada em interesses ou em princípios - calor contra luz - estão tão difundidas no pensamento político, que talvez baste dizer, simplesmente, que são inúteis. (Walzer, 2008, p. 189)

Essa conclusão, segundo ele, longe de ser um argumento contra a razão, é, na verdade, um corretivo importante concernente ao racionalismo liberal.

LEIVAS. Cláudio R. C. Passion, democracy and deliberation in Hobbes and Walzer. Trans/Form/Ação, São Paulo, v.32(2), 2009, p.63-74.

- ABSTRACT: The article examines the relationship among passion, democracy and deliberation in the thought of Hobbes and Walzer. Reasons are presented by which those two thinkers are positioned in a critical way regarding the deliberations in the democratic governments' extent. The relationship between reason and passion is also examined inside the central problem of our comparative study.

- KEYWORDS: democracy, deliberation, reason, passion.

\section{Referências bibliográficas}

FISHKIN, J. Deliberative Democracy. In: The Blackwell Guide to Social and Political Philosophy. Ed. de Robert L. Simon. Oxford: Blackwell, 2002.

HOBBES, T. Do cidadão. São Paulo: Martins Fontes, 1992.

Os elementos da lei natural e política: Tratado da natureza humana: Tratado do corpo político. São Paulo: Ícone, 2002.

Leviatã. São Paulo: Martins Fontes, 2003.

STRAUSS, L. The Political Philosophy of Hobbes. Chicago: Chicago University Press, 1996.

WALZER, M. Política e paixão. São Paulo: WMF Martins Fontes, 2008. 